\title{
АДАПТИВНА СИСТЕМА КЕРУВАННЯ КУТОМ ТАНГАЖУ ЛІТАЛЬНИХ ОБ'СКТІВ
}

\section{Вступ}

У багатьох випадках динамічні та статичні властивості системи керування можуть змінюватися у часі, змінюються зовнішні завади, які діють на об'єкт керування. У цих випадках регулятори з жорсткими ( незмінними ) параметрами не можуть забезпечити потрібні режими роботи. Отже, необхідно змінювати налаштування керуючих пристроїв, параметри деяких елементів системи, вводити у систему канали компенсації, тобто переходити до самонастроювальних (адаптивних ) систем керування. Серед адаптивних систем керування широке застосування знайшли системи, в яких якість перехідних процесів закладаеться в динаміку еталонної моделі, яка представляеться в аналоговій або цифровій формі у вигляді математичної моделі. В системах з еталонною моделлю шляхом порівняння вимірювального та заданого показників якості формуються додаткові сигнали, які забезпечують задані показники якості. Такий метод формування закону керування зветься сигнальною настройкою.

Розглянемо типову блок-схеми адаптивної системи з еталонною моделлю та додатковим сигналом керування (рис. 1 ). Пристрій керування $\Pi \kappa_{2}$ на основі інформації про розбіжність векторів $X_{M}$ стану моделі та $X(t)$ самої системи виробляе вектор додаткового керування $m(t)$, який впливае на основний пристрій керування $\Pi K_{1}$.

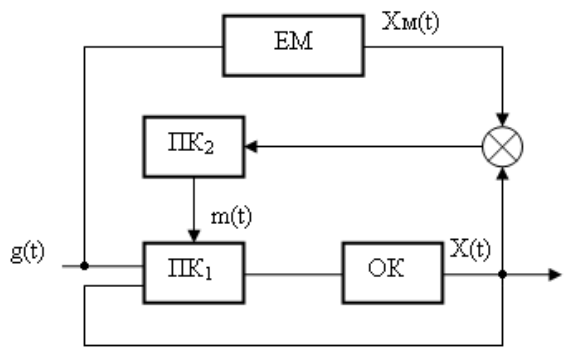

Рис. 1 - Типова адаптивна система з еталонною моделлю.

При параметричних методах адаптації синтез законів керування як правило дає нелінійні закони зміни параметрів $\Pi \kappa_{1}$, що значно ускладнюе задачу їх реалізації. При сигнальних методах реалізацію вектора додаткового керування в реальних умовах можна виконати тільки за допомогою самого $\Pi \kappa_{1}$ в прямому каналі керування, що обмежуе можливість впливати безпосередньо на всі змінні стану об'єкта керування.

(C) С.В. Шпіт, А.В. Почекайлов, 2010 


\section{Постановка задачі}

Значна частина теорії побудови систем керування базуеться на використанні зворотних зв'язків по змінним стану. Однак, на практиці не всі змінні стану доступні до вимірювання, i, як правило, вимірюються тільки вихідні змінні об'екта керування. В $[1,2,3,4]$ показано, що якщо керований процес є спостережливим, то можна побудувати пристрій спостереження, який на основі інформації про вхідні та вихідні сигнали відновлюе оцінки змінних стану, на основі яких формуються сигнали зворотних зв'язків для керування процесом. Для цих методів характерно те, що структура регулятора обираеться апріорі на основі інформації про об'єкт керування. Класичний спостерігач стану, поданий на рис. 1 , повинен будуватися таким чином, щоб відновлений стан $Y c(t)$ був як можна ближче до дійсного стану $Y(t)$. При цьому вважається що структура пристрою, що спостерігає ідентична по відношенню до дійсної системи керування, що значно обмежуе можливі області використання таких методів синтезу при дії на об'ект керування неконтрольованих зовнішніх збурень та у разі неконтрольованих змін параметрів самого об'єкта керування. В роботах $[5,6,7]$ була показана можливість застосування спостерігача для керування такими об'єктами. На основі вимірювання вихідних координат системи керування та пристрою, що спостерігає, здобуваеться інформація про відхилення вихідних координат об'єкта керування від координат спостерігача $\Delta Y(t)=Y(t)-Y c(t)$. Але задача спостерігача буде полягати не в оцінці координат змінних стану $X c(t)$, а в тому, щоб привести вихідні координати $Y(t)$ об'єкта керування до координат $Y c(t)$, які будемо вважати заданими. Для розв'язання такої задачі необхідно до керуючого впливу $U(t)$ додавати компенсуючи керування $\Delta U k(t)=F(\Delta Y(t))$ (рис. 2). Отже, тепер задачею спостерігача стає задача стеження за відхиленням дійсного процесу від заданого та виробки вектору додаткового керування, який подається на об'єкт керування.

В цьому разі спостерігач діє як еталонна модель, тобто стає деяким керуючим пристроєм, який приводить вихідні координати об'єкта керування до заданих. Такий керуючий спостерігач будемо називати дуальним [7]. В [6] показано, що при $L k=W k(s) \gg 1$ еквівалентна передаточна функція всієї системи керування буде визначатися передаточною функцією дуального спостерігача. При виконанні ціеї умови система керування стає інваріантною до впливу зовнішніх збуджень, а динамічні властивості (перехідні процеси) наближаються до процесів, які визначаються дуальним спостерігачем.

Припустимо, що динаміка основного контура системи керування описуеться системою лінійних диференційних рівнянь із змінними параметрами вигляду $\dot{x}(t)=A(t) x(t)+B(t) g(t)+m(t)+B_{v}(t) v(t)$, а задана динаміка визначаеться дуальним спостерігачем, тобто $\dot{x}_{s}(t)=A x(t)+B g(t)$, де матриці $A$ та $B$ е сталими і відповідають одному із заданих режимів роботи.

Вектор розбіжності змінних стану дуального спостерігача та системи 


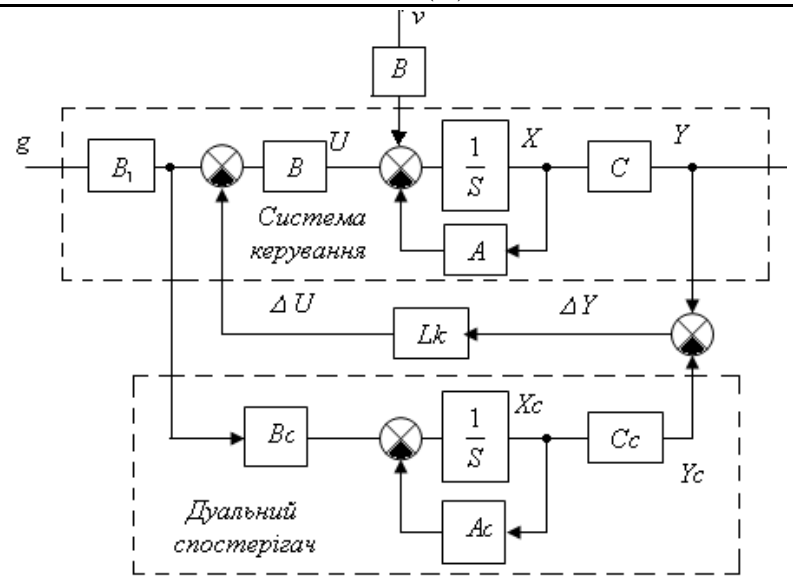

Рис. 2 - Система керування з дуальним спостерігачем

$\varepsilon(t)=x_{м}(t)-x(t)$, або $\Delta y(t)=C x_{м}(t)-C(t) x(t)$. Тоді, при відсутності зовнішнього впливу $v(t)=0$, можна записати $\dot{\varepsilon}(t)=A(t) \varepsilon(t)-\Delta A x(t)-$ $\Delta D g(t)-m(t)$, де $\Delta A=A(t)-A, \Delta B=B(t)-B$. Отже треба знайти такий вектор керування $m(t)$, щоб можна було забезпечити асимптотичне збігання в цілому системи з дуальним спостерігачем. При використанні прямого методу Ляпунова фрункцію Ляпунова слід обирати у вигляді додатньо-визначеної квадратичної форми $V=\varepsilon^{T} P \varepsilon$. При цьому похідна функції Ляпунова $\dot{V}=-\varepsilon^{T} Q \varepsilon-2 \gamma$, де $Q=A^{T} P+P A, \gamma=\varepsilon^{T} P(\Delta A x+$ $\Delta D g+m)$ буде від'ємно-визначеною, якщо матриця $Q>0$ та $\gamma \geqslant 0$.

В реальних системах сформувати $n$-мірний вектор не представляеться можливим, тому що подавати додатковий сигнал керування на внутрішні змінні стану об'екта керування практично неможливо.

Розглянемо типову систему керування кута тангажу на прикладі літака F-101, яку представлено на рис. 3.

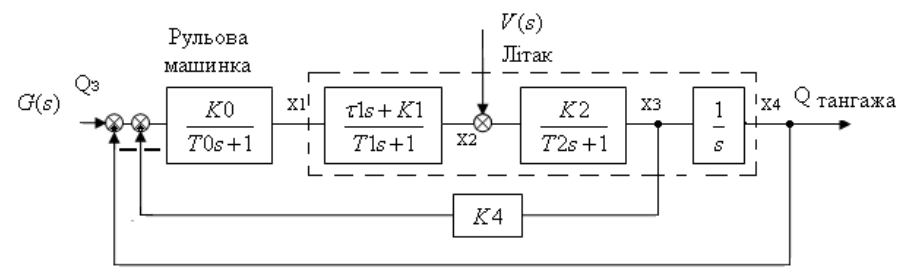

Рис. 3 - Система керування кута тангажу

Параметри системи керування

$$
\begin{array}{llll}
\mathrm{K} 0:=8 & \mathrm{~T} 0:=0.2 & \mathrm{~T} 1:=0.318 & \mathrm{~T} 2:=0.284 \\
\tau 1:=2.25 & \mathrm{~K} 1:=2 & \mathrm{~K} 2:=0.608
\end{array}
$$


Для теоретичних розрахунків була застосована векторно - матрична модель (для розрахунків використовуеться програма MathCAD 13):

$$
\begin{aligned}
& \mathrm{A} 0:=\left[\begin{array}{cccc}
\frac{-1}{\mathrm{~T} 0} & 0 & 0 & \frac{-\mathrm{K} 0}{\mathrm{~T} 0} \\
\frac{\tau 1}{\mathrm{~T} 1} \cdot\left(\frac{\mathrm{K} 1}{\tau 1}-\frac{1}{\mathrm{~T} 1}\right) & \frac{-1}{\mathrm{~T} 1}\left[\frac{\tau 1}{\mathrm{~T} 1} \cdot\left(\frac{\mathrm{K} 1}{\tau 1}-\frac{1}{\mathrm{~T} 1}\right)\right] \\
\frac{\tau 1}{\mathrm{~T} 1} \cdot \frac{\mathrm{K} 2}{\mathrm{~T} 2} & \frac{\mathrm{K} 2}{\mathrm{~T} 2} & \frac{-1}{\mathrm{~T} 2}-\frac{\tau 1}{\mathrm{~T} 1} \cdot \frac{\mathrm{K} 2}{\mathrm{~T} 2} & 0 \\
0 & 0 & 1 & 0
\end{array}\right] \quad \mathrm{B} 0:=\left(\begin{array}{cc}
\frac{\mathrm{K} 0}{\mathrm{~T} 0} & 0 \\
0 & 0 \\
0 & \frac{\mathrm{K} 2}{\mathrm{~T} 2} \\
0 & 0
\end{array}\right) \\
& \mathrm{C} 0:=\left(\begin{array}{llll}
0 & 0 & 0 & 1
\end{array}\right) \quad \mathrm{C} 01:=\left(\begin{array}{llll}
1 & 0 & 0 & 0
\end{array}\right) \quad\left(\begin{array}{llll}
1 & 0 & 0 & 0 \\
0 & 1 & 0 & 0 \\
0 & 0 & 1 & 0 \\
0 & 0 & 0 & 1
\end{array}\right)
\end{aligned}
$$$$
\mathrm{W} 0(\mathrm{~s}):=\mathrm{C} 0 \cdot(\mathrm{s} \cdot \mathrm{IO}-\mathrm{AO})^{-1} \cdot \mathrm{BO} \mid \begin{aligned}
& \text { collect,s } \\
& \text { float,4 }
\end{aligned} \rightarrow
$$$$
\left[40.00 \cdot \frac{13.46+15.15 \cdot s}{s^{4}+26.81 \cdot s^{3}+201.9 \cdot s^{2}+1070 \cdot s+538.6} 2.141 \cdot(s+3.145) \cdot \frac{s+5}{s^{4}+26.81 \cdot s^{3}+201.9 \cdot s^{2}+1070 \cdot s+538.6}\right]
$$$$
\mathrm{WO1}(\mathrm{s}):=\mathrm{CO1} \cdot(\mathrm{s} \cdot \mathrm{IO}-\mathrm{AO})^{-1} \cdot \mathrm{BO} \mid \begin{aligned}
& \text { collect,s } \\
& \text { float,4 }
\end{aligned} \rightarrow
$$$$
\left[40.00 \cdot s \cdot \frac{s^{2}+21.81 \cdot s+92.88}{s^{4}+26.81 \cdot s^{3}+201.9 \cdot s^{2}+1070 \cdot s+538.6}(-2.141) \cdot \frac{40 \cdot s+125.8}{s^{4}+26.81 \cdot s^{3}+201.9 \cdot s^{2}+1070 \cdot s+538.6}\right]
$$

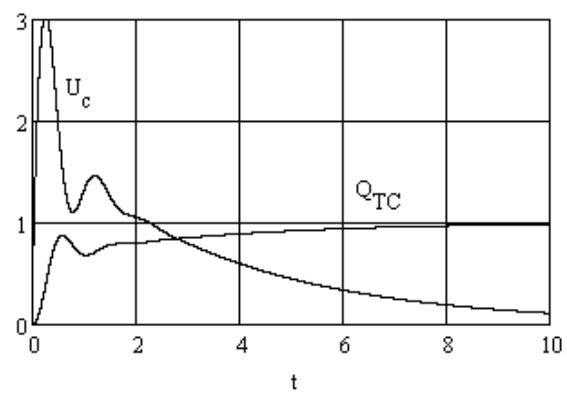

Рис. 4 - Перехідні процеси в системі керування кутом тангажу

Аналіз графіків показуе, що для забезпечення потрібної динаміки не- 
обхідно застосовувати значні керуючі впливи $U_{C}$. Крім того при зміні режимів роботи (наприклад, зміна висоти польоту) параметри об'екту керування можуть змінюватися, що створюе необхідність застосовувати параметричні методи адаптації параметрів пристрою керування $\Pi \kappa_{1}$. При цьому значно ускладнюеться система керування. Дія на систему неконтрольованих збуджень $V(t)$ також призводить до необхідності застосування складних законів керування.

В $[5,6,7]$ показана можливість застосування керуючого спостерігача (дуального спостерігача) у якості пристрою, який забезпечує потрібну динаміку перехідних процесів, компенсацію неконтрольованих збуджень та зміну параметрів об'єкта керування. Включення такого дуального спостерігача показано на рис.5. Приведені необхідні аналітичні порівняльні розрахунки на основі застосування векторно - матричних методів.

$$
\begin{array}{llll}
\multicolumn{4}{l}{\text { Параметри системи керування }} \\
\mathrm{K} 0:=6 & \mathrm{~T} 0:=0.2 \quad \tau 1:=2.25 \quad \mathrm{~K} 1:=2 \quad \mathrm{~T} 1:=0.318 \\
\mathrm{~K} 2:=0.608 & \mathrm{~T} 2:=0.284 \quad \mathrm{~K} 4:=10 \quad \mathrm{~K} 5:=10 \\
\mathrm{~g} 1(\mathrm{t}):=1 & \mathrm{~g} 1(\mathrm{~s}):=\mathrm{g} 1(\mathrm{t}) \text { laplace, } \mathrm{t} \rightarrow \frac{1}{\mathrm{~s}} \quad \mathrm{~g} 2(\mathrm{t}):=0 \quad \mathrm{~g} 2(\mathrm{~s}):=\mathrm{g} 2(\mathrm{t}) \text { laplace, } \mathrm{t} \rightarrow 0
\end{array}
$$

Параметри дуального спостерігача, який задає бажану якість перехідних процесів: К3:=0.5 Т3:=1

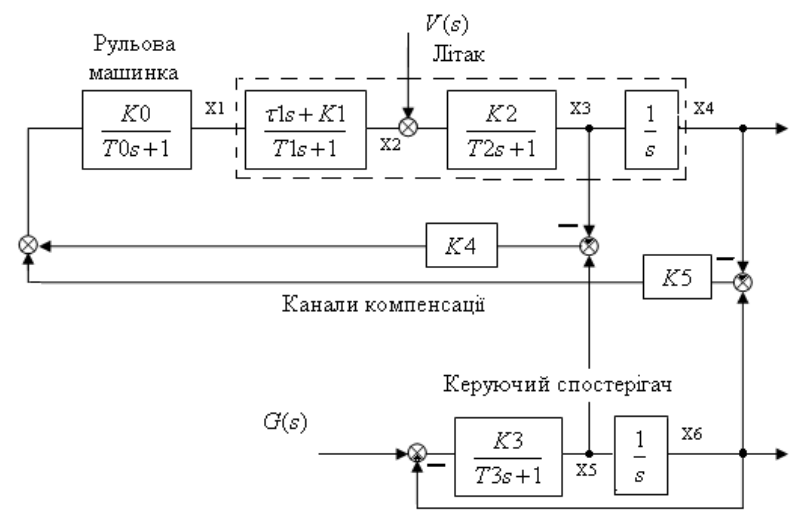

Рис. 5 - Система керування із дуальним спостерігачем

Векторно - матрична модель системи керування 


$$
\mathrm{A}:=\left[\begin{array}{cccccc}
\frac{-1}{\mathrm{~T} 0} & 0 & \frac{-\mathrm{K} 0 \cdot \mathrm{K} 4}{\mathrm{~T} 0} & -\frac{\mathrm{K} 0 \cdot \mathrm{K} 5}{\mathrm{~T} 0} & \frac{\mathrm{K} 0 \cdot \mathrm{K} 4}{\mathrm{~T} 0} & \frac{\mathrm{K} 0 \cdot \mathrm{K} 5}{\mathrm{~T} 0} \\
\frac{\tau 1}{\mathrm{~T} 1} \cdot\left(\frac{\mathrm{K} 1}{\tau 1}-\frac{1}{\mathrm{~T} 1}\right) & \frac{-1}{\mathrm{~T} 1} & 0 & 0 & 0 & 0 \\
\frac{\tau 1 \cdot \mathrm{K} 2}{\mathrm{~T} 1 \cdot \mathrm{T} 2} & \frac{\mathrm{K} 2}{\mathrm{~T} 2} & \frac{-1}{\mathrm{~T} 2} & 0 & 0 & 0 \\
0 & 0 & 1 & 0 & 0 & 0 \\
0 & 0 & 0 & 0 & \frac{-1}{\mathrm{~T} 3} & \frac{-\mathrm{K} 3}{\mathrm{~T} 3} \\
0 & 0 & 0 & 0 & 1 & 0
\end{array}\right] \quad \mathrm{g}(\mathrm{s}):=\left(\begin{array}{c}
\mathrm{g} 1(\mathrm{~s}) \\
\mathrm{g} 2(\mathrm{~s})
\end{array}\right)
$$

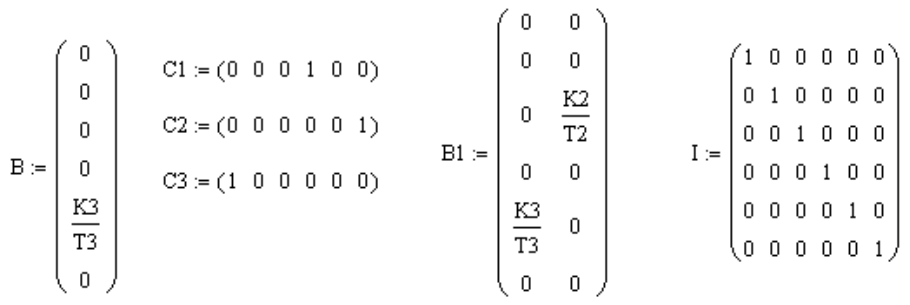

Розрахунок передаточних фрункцій

$$
\begin{aligned}
& \mathrm{W} 1(\mathrm{~s}):=\mathrm{C} 1 \cdot(\mathrm{s} \cdot \mathrm{I}-\mathrm{A})^{-1} \cdot \mathrm{B} 1 \mid \begin{array}{l}
\text { collect, } \mathrm{s} \\
\text { float, } 4
\end{array} \rightarrow \\
& {\left[s \cdot \frac{8584 \cdot s+4039 \cdot+4544 \cdot s^{2}}{s^{6}+12.67 \cdot s^{5}+4601 \cdot s^{4}+.1323 e s \cdot s^{3}+.1497 e 5 \cdot s^{2}-8359 \cdot s+2020} .\right.} \\
& \left.2.141 \cdot\left(s^{2}+s+.5000\right) \cdot(s+3.145) \cdot \frac{s+5}{s^{6}+12.67 \cdot s^{5}+4601 \cdot s^{4}+.1323 e 5 \cdot s^{3}+.1497 e s \cdot s^{2}+8359 \cdot s+2020 .}\right] \\
& \mathrm{W} 2(\mathrm{~s}):=\mathrm{C} 2 \cdot(\mathrm{s} \cdot \mathrm{I}-\mathrm{A})^{-1} \cdot \mathrm{B} 1 \mid \begin{array}{l}
\text { collect, } \mathrm{s} \\
\text { float, } 4
\end{array} \rightarrow \\
& \left(\frac{s^{4}+11 \cdot 67 \cdot s^{3}+4589 \cdot s^{2}+8639 \cdot s+4739}{s^{6}+12.67 \cdot s^{5}+4601 \cdot s^{4}+.1323 e s \cdot s^{3}+.1497 e s \cdot s^{2}+8359 \cdot s+2020} .0\right) \\
& \left(5 \cdot \frac{s^{4}+11 \cdot 67 \cdot s^{3}+4589 \cdot s^{2}+8639 \cdot s+4339}{s^{6}+12.67 \cdot s^{5}+4601 \cdot s^{4}+.1323 e s \cdot s^{3}+.1497 e s \cdot s^{2}+8359 \cdot s+2020} 0\right) \\
& \mathrm{W} 3(\mathrm{~s}):=\mathrm{C} 3 \cdot(\mathrm{s} \cdot \mathrm{I}-\mathrm{A})^{-1} \cdot \mathrm{B} 1 \mid \begin{array}{l}
\text { collect, s } \\
\text { float,4 }
\end{array} \rightarrow \\
& {\left[5 \cdot(300 \cdot s+300) \cdot(s+3.145) \cdot(s+3.521) \cdot \frac{s}{s^{6}+12.67 \cdot s^{5}+4601 \cdot s^{4}+.1323 e s \cdot s^{3}+.1497 \mathrm{e} 5 \cdot s^{2}+8359 \cdot s+2020} .\right.} \\
& \left.(-2.141) \cdot\left(300 \cdot \mathrm{s}^{3}+600 \cdot \mathrm{s}^{2}+450 \cdot \mathrm{s}+150\right) \cdot \frac{\mathrm{s}+3.145}{\mathrm{~s}^{6}+12.67 \cdot \mathrm{s}^{5}+4601 \cdot \mathrm{s}^{4}+.1323 \mathrm{e} \cdot \mathrm{s}^{3}+.1497 \mathrm{e} 5 \cdot \mathrm{s}^{2}+8359 \cdot \mathrm{s}+2020 .}\right]
\end{aligned}
$$

Розрахунок перехідних процесів 


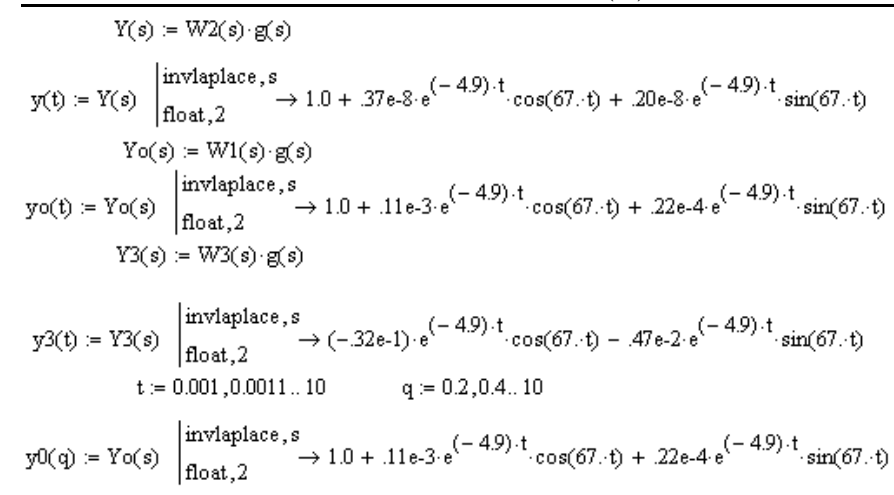

Для порівняння розраховуються перехідні процеси типової системи керування при заданих параметрах:

$$
\begin{aligned}
& \mathrm{K} 0:=8 \quad \mathrm{~T} 0:=0.2 \quad \mathrm{~T} 1:=0.318 \quad \mathrm{~T} 2:=0.284 \\
& \tau 1:=2.25 \quad \mathrm{~K} 1:=2 \quad \mathrm{~K} 2:=0.608 \\
& \mathrm{~A} 0:=\left[\begin{array}{cccc}
\frac{-1}{\mathrm{~T} 0} & 0 & 0 & \frac{-\mathrm{K} 0}{\mathrm{~T} 0} \\
\frac{\tau 1}{\mathrm{~T} 1} \cdot\left(\frac{\mathrm{K} 1}{\tau 1}-\frac{1}{\mathrm{~T} 1}\right) & \frac{-1}{\mathrm{~T} 1}\left[\frac{\tau 1}{\mathrm{~T} 1} \cdot\left(\frac{\mathrm{K} 1}{\tau 1}-\frac{1}{\mathrm{~T} 1}\right)\right] \\
\frac{\tau 1}{\mathrm{~T} 1} \cdot \frac{\mathrm{K} 2}{\mathrm{~T} 2} & \frac{\mathrm{K} 2}{\mathrm{~T} 2} & \frac{-1}{\mathrm{~T} 2}-\frac{\tau 1}{\mathrm{~T} 1} \cdot \frac{\mathrm{K} 2}{\mathrm{~T} 2} & 0 \\
0 & 0 & 1 & 0
\end{array}\right] \quad \mathrm{B} 0:=\left(\begin{array}{cc}
\frac{\mathrm{K} 0}{\mathrm{~T} 0} & 0 \\
0 & 0 \\
0 & \frac{\mathrm{K} 2}{\mathrm{~T} 2} \\
0 & 0
\end{array}\right) \\
& \mathrm{C} 0:=\left(\begin{array}{llll}
0 & 0 & 0 & 1
\end{array}\right) \\
& \mathrm{C} 01:=\left(\begin{array}{llll}
1 & 0 & 0 & 0
\end{array}\right) \\
& \mathrm{I0}:=\left(\begin{array}{llll}
1 & 0 & 0 & 0 \\
0 & 1 & 0 & 0 \\
0 & 0 & 1 & 0 \\
0 & 0 & 0 & 1
\end{array}\right)
\end{aligned}
$$$$
\mathrm{W} 0(\mathrm{~s}):=\mathrm{C} 0 \cdot(\mathrm{s} \cdot \mathrm{IO}-\mathrm{A0})^{-1} \cdot \mathrm{BO} \mid \begin{aligned}
& \text { collect, }, \mathrm{s} \\
& \text { float, } 4
\end{aligned} \rightarrow
$$$$
\text { W01(s) : }=\mathrm{C} 01 \cdot(\mathrm{s} \cdot \mathrm{I0}-\mathrm{A0})^{-1} \cdot \mathrm{BO} \mid \begin{aligned}
& \text { collect,s } \\
& \text { float, } 4
\end{aligned} \rightarrow
$$$$
\mathrm{z}(\mathrm{s}):=\mathrm{W}(\mathrm{s}) \cdot g(s)
$$$$
\mathbb{z}(t):=\mathbb{Z}(s) \mid \begin{aligned}
& \text { invlaplace, } s \\
& \text { float, } 2
\end{aligned} \rightarrow 1.0-.11 \cdot \mathrm{e}^{(-19) \cdot \mathrm{t}}-.47 \cdot \mathrm{e}^{(-3.6) \cdot t} \cdot \cos (6.1 \cdot t)-.66 \cdot \mathrm{e}^{(-3.6) \cdot \mathrm{t}} \cdot \sin (6.1 \cdot \mathrm{t})
$$$$
\mathrm{z} 1(\mathrm{~s}):=\mathrm{W01}(\mathrm{s}) \cdot \mathrm{g}(\mathrm{s})
$$$$
z 1(t):=z 1(s) \mid \begin{aligned}
& \text { invlaplace, s } \\
& \text { float, } 2
\end{aligned} \rightarrow(-.32) \cdot e^{(-19) \cdot t}-3.4 \cdot e^{(-3.6) \cdot t} \cdot \cos (6.1 \cdot t)+3.9 \cdot e^{(-3.6) \cdot t} \cdot \sin (6.1 \cdot t)
$$

Результати аналітичних розрахунків представлені на рис. 6

Аналіз аналітичних розрахунків показуе, що запропонований метод побудови системи керування із заданими показниками якості повністю 


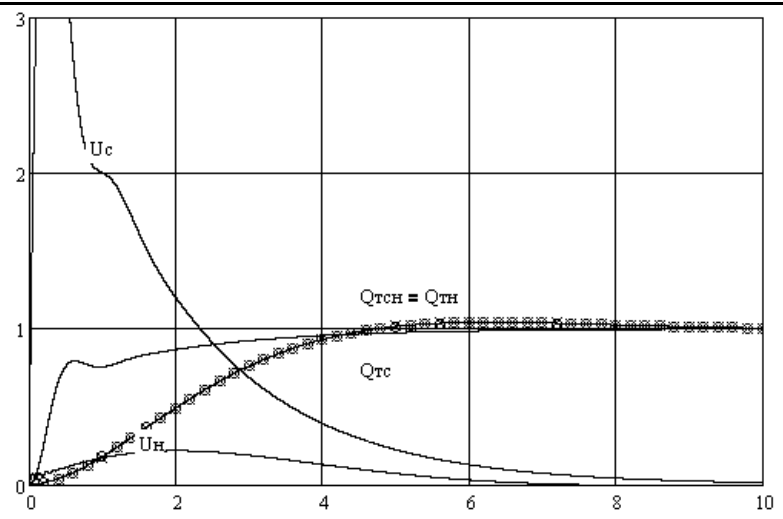

Рис. 6 - Результати аналітичних розрахунків

задовольняе умовам поставленої задачі. Також були виконані розрахунки перехідних процесів при дії на систему керування та типову систему неконтрольованого збудження типу регулярної „бовтанки”

$$
\mathrm{V}(\mathrm{t}):=1 \sin (5 \cdot \mathrm{t}) \quad \mathrm{V}(\mathrm{s}):=\mathrm{V}(\mathrm{t}) \text { laplace, } \mathrm{t} \rightarrow \frac{\mathrm{s}}{\mathrm{s}^{2}+25}
$$

Результати аналітичних розрахунків (рис. 7) показують, що типова система керування у перехідних процесах не компенсуе такі завади (див. криву $Q_{T C}$ ), тоді як запропонована система практично не реагуе на збуджуючий вплив $\left(Q_{T C H}=Q_{T H}\right)$, при цьому показники якості систем з дуальним спостерігачем залишаються стабільними.

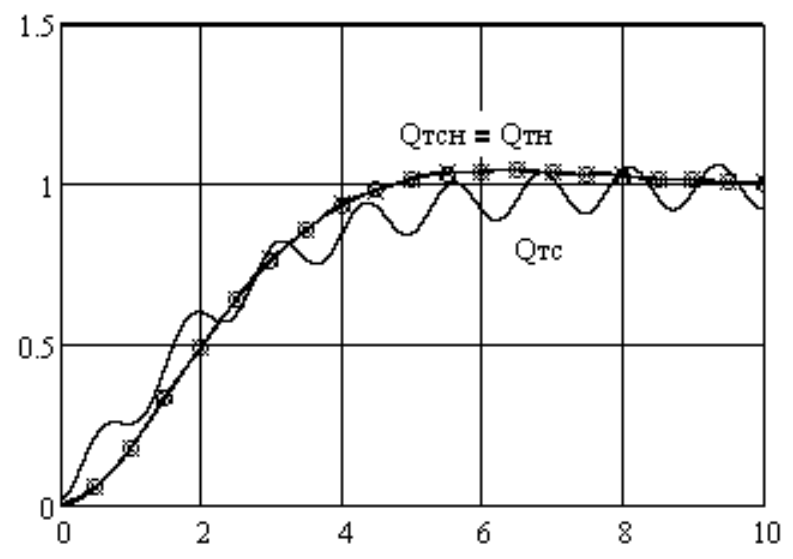

Рис. 7 - Вплив регулярної завади

Більш детальні дослідження запропонованого методу побудови адаптивної системи з дуальним спостерігачем в системі керування ку- 
том тангажу проводилися на універсальному лабораторному комплексі „SHS-TAK”, розробленому на кафедрі Технічної кібернетики Національного технічного університеті „Київський політехнічний інститут”. Схему набору моделі системи керування з дуальним спостерігачем представлено на рис. 8.

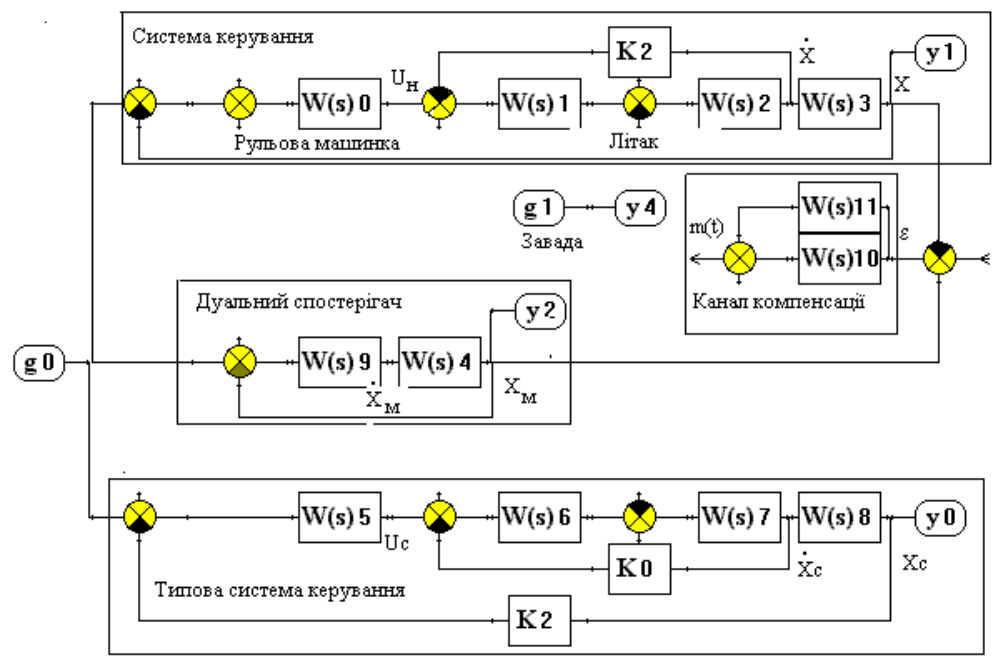

Рис. 8 - Схема моделі системи керування з дуальним спостерігачем

Аналіз результатів: 1) На рис. 9 представлені перехідні процеси при виключеному каналі компенсації; перехідні процеси типової системи керування та системи, що розглядаеться, співпадають $(X=X c)$; експериментальні дані співпадають з аналітичними; 2) На рис. 10 приведені перехідні процеси при включеному каналі компенсації, перехідний процес $X(t)$ задається дуальним спостерігачем $\left(X=X_{M}\right)$; 3) На рис. 11, 12 даються результати дії на систему керування детермінованої завади $V \cdot 1(t)$ при виключеному та включеному каналу компенсації відповідно. Завада подавалася із затримкою у 5 сек. відносно моменту прикладання задавального впливу $g(t)$. При цьому в типової системи керування спостерігаються значні відхилення, тоді як у запропонованої присутня повна компенсація таких впливів $\left(X=X_{M}\right)$;

4) На рис.13 показані результати дослідження дії випадкової завади, яка впливає на внутрішні змінні стану об'єкту керування (літака), з яких можна зробити висновок - система з дуальним спостерігачем компенсує неконтрольовані зовнішні збудження.

Для підвищення швидкості збігання процесів адаптації слід підвищувати коефіцієнт передачі каналу компенсації, а для стійкості - включати в канал компенсації диференцюючу складову $W(s) 10=\frac{5 s+30}{0.01 s+1}$. 
"ACAY" - 16(36) 2010
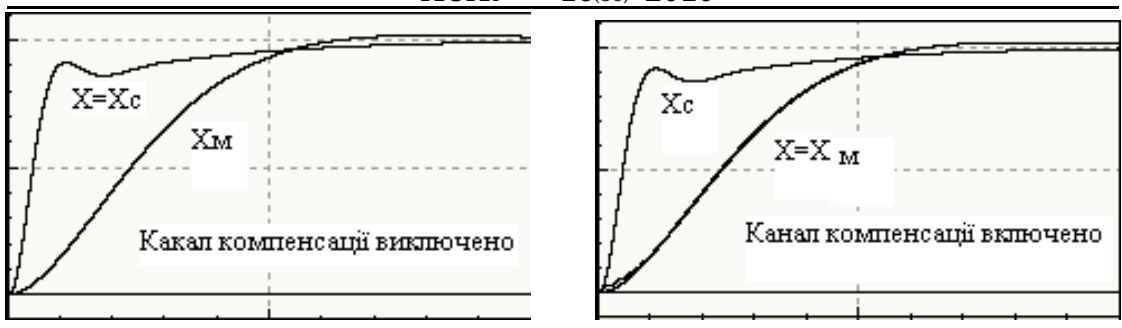

Рис. 9 - Перехідні процеси при вимкнутому каналі компенсації

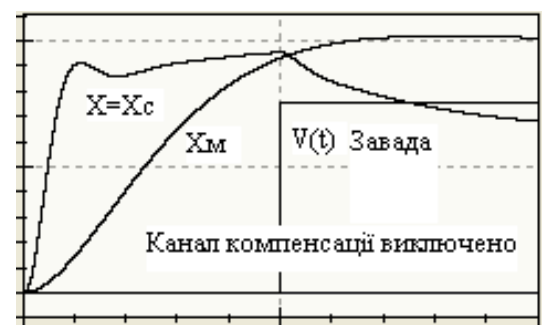

Рис. 11 - Результат дії детермінованої завади при вимкнутому каналі компенсації
Рис. 10 - Перехідні процеси при включеному каналі компенсації

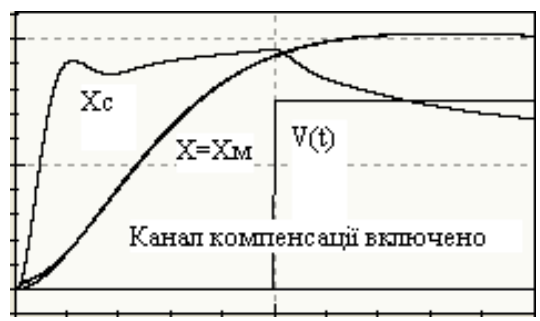

Рис. 12 - Результат дії детермінованої завади при включеному каналі компенсації

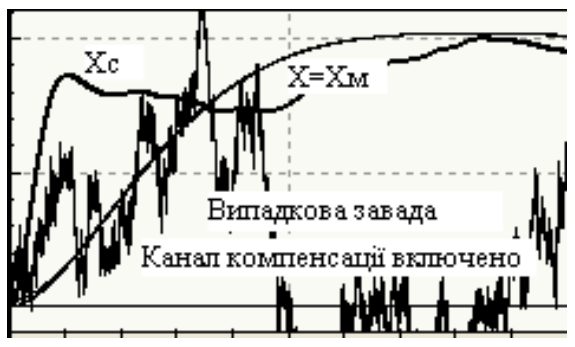

Рис. 13 - Результати дії випадкової завади

Для надання системі керування властивостей робастості в канал компенсації необхідно додавати інтегральну складову $W(s) 11=\frac{0 s+50}{1 s+0}$. Таким чином канал компенсації набуває властивостей ПІД-регулятора. Оскільки в адаптивній системі з еталонною моделлю при значних коефіцієнтах передачі каналу компенсації загальна передаточна функція всієї системи керування практично дорівнюе передаточної функції еталонної моделі (дуального спостерігача) [6], досліджувалась можливість спрощення реалізації адаптивної системи: основний канал рульова ма- 
шинка - літак розглядався як розімкнутий (головний зворотний зв'язок виключено); задавальний вплив $g(t)$ подавався тільки на дуальний спостерігач (рис. 14).

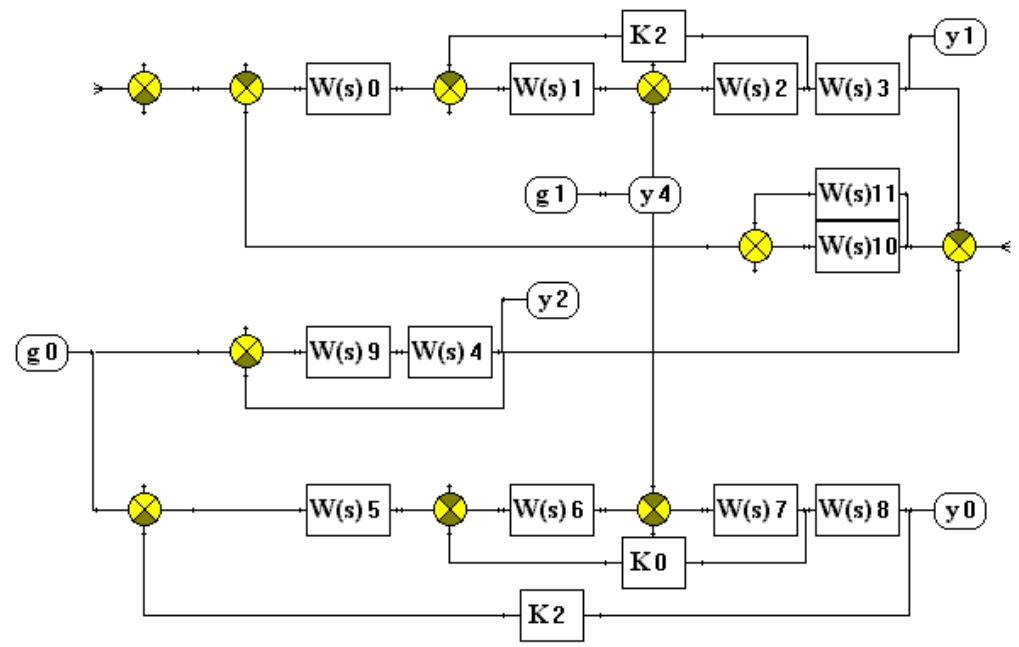

Рис. 14 - Спрощена система керування кута тангажа

Результати дослідження (рис. 15) показали повну працездатність системи керування з розімкнутим прямим каналом передачі задавального впливу. Динамічні властивості системи керування не змінюються.

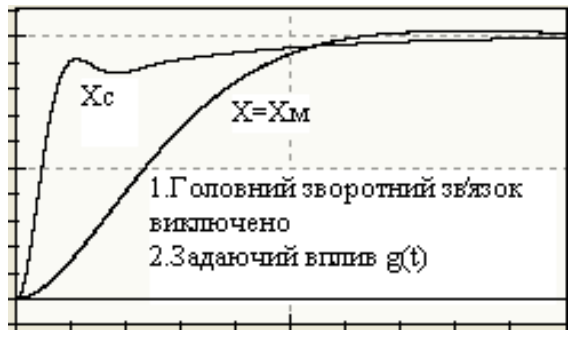

Рис. 15 - Перехідні процеси в спрощеній системі керування

\section{Висновки}

Теоретичні та експериментальні дослідження побудови різноманітних автоматичних систем керування з дуальним спостерігачем показали високу ефективність запропонованих методів при значному спрощенні їх фрізичної реалізації. При цьому знімається проблема корекції параметрів як об'екта керування так і регулятора, а сама система керування набувае властивостей грубості ( робастості ) навіть при значних 
змінах параметрів системи та впливу неконтрольованих завад у широкому діапазоні.

Запропонований спосіб побудови систем керування може бути використаний у випадках, коли математична модель системи побудована, але створення натурної моделі для експериментів неможливе або пов'язано із значними фінансовими витратами.

\section{Література}

1. 1. Тютюнник А.Г. Оптимальні і адаптивні системи автоматичного керування: Навчальний посібник. - Житомир: ЖITI,1998.-512c.

2. 2. Летов А.М. Динамика полета и управление, М., “ Наука”.1969. 360c.

3. 3. Топчеев Ю. И., Потемкин В. Г., Иваненко В. Г. Системы стабилизации. М., "Машиностроение”, 1974. 248c.

4. 4. Иващенко Н.Н. Автоматическое регулирование. Теория и элементы систем. Учебник для вузов. М., “Машиностроение”. 1978. 736с.

5. 5. Шпіт C.В., Янцеловський С.Г., Ткаченко О.І.. Системи автоматичного керування з еталоном - спостерігачем // Адаптивні системи автоматичного управління. -2008- 12(32).- с. 145 - 151.

6. 6. Шпіт C.В., Семчишин А.В. Автономна багатомірна система керування з еталонами - спостерігачами // Адаптивні системи автоматичного управління. -2009 - 13(33).- с. .

7. Шпіт С.В. Дуальний спостерігач в системах автоматичного керування // Адаптивні системи автоматичного управління. -2009 - 14(34).c. .

Отримано 06.03.2010 р. 